\title{
LO FANTÁSTICO EN LA INTERPRETACIÓN ACTUAL DEL MITO DE ORFEO Y EURÍDICE DE DINO BUZZATI POEMA A FUMETTI
}

\author{
Miguel Ángel Muro \\ miguel-angel.muro@unirioja.es \\ Universidad de La Rioja
}

Recibido: 14-09-2016

Aceptado: 14-05-2017

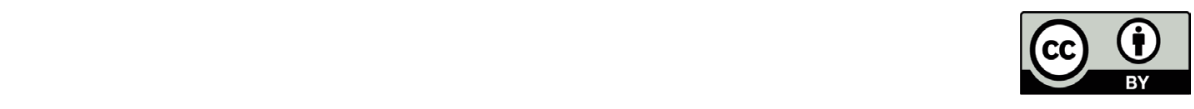

RESUMEN

El propósito de este artículo es estudiar la llamativa novela gráfica de Dino Buzzati (1906-1972), Poema a fumetti (1969), donde se trata un tema interesante en el ámbito de lo fantástico como es el del descenso a los infiernos, en una reescritura actual del mito clásico griego de Orfeo y Eurídice. Buzzati, maestro del fantástico en la literatura italiana, vierte el mito en cómic y lo impregna de la sexualidad y la angustia propias de la sensibilidad contemporánea.

Palabras Clave: Buzzati, Orfeo y Eurídice, cómic, sexualidad, angustia.

\section{Abstract}

This paper studies Poema a fumetti, the striking graphic novel Dino Buzzati (1906-1972), published in 1969. This novel, which moves within the realms of the fantastic, is centered on the topic of the descent into hell, and thus it revisits the Greek myth of Orpheus and Eurydice. Buzatti, a master of the fantastic in Italian literature, distills the myth in comic and impregnates it with the sexuality and anguish of contemporary sensibility.

Keywords: Buzzati, Orpheus and Euridice, comic, sexuality, anguish.

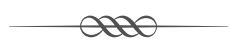


¿Te acuerdas cuánto odiábamos a la muerte? ¡Cómo nos amargaba la vida! Y los cementerios, ¿te acuerdas? Y los cipreses. Y las luces en la noche, y los fantasmas, los fantasmas con cadenas que salían de sus tumbas... Y el pensamiento sobre el más allá, las discusiones que se hacían a ese respecto, aquel misterio, ¿te acuerdas?

Dino Buzzati, «Extraños nuevos amigos»

\section{La APARición de Poema a fUMetTI}

En 1969 Dino Buzzati causó sorpresa en el ambiente literario italiano con la publicación de Poema a fumetti, ya que, aunque era bien conocido como escenógrafo y pintor (además, por supuesto, de ser un periodista, poeta, novelista, autor de teatro e ilustrador respetado y admirado: una especie de hombre del Renacimiento en el siglo xx), no se esperaba que hiciera su aparición en el mundo del cómic y menos que lo hiciera con la potencia creativa de un texto que le valió el premio «Paese Sera» al mejor cómic del año. Pero no se trató de una decisión súbita o irreflexiva, ni de un trabajo menor o de pasatiempo; bien al contrario, Buzzati trabajó en este proyecto cerca de dos años, ya en plena madurez creativa, y lo calificó como obra que le salía «de las vísceras, como El desierto de los Tártaros o Un amor» (Buzzati, 2006: 6); la crítica, por su parte, la entendió también como «un epílogo ilustrado de todos los lugares morales y fantásticos de su autor» (Alberico Sala, en Buzzati, 2006: 6).

\section{Lo FANTÁSTICO EN LA OBRA DE BUZZATI}

En efecto, Buzzati había ido construyendo estos lugares existenciales y fantásticos en novelas como Bàrnabo delle montagne (1933), Il segreto del Bosco Vecchio (1935) o Il deserto dei Tartari (1940, su obra maestra), y en libros de relatos como I sette messaggeri (1942), Sessanta racconti (1958, premio Strega) o Il colombre (1966).

\subsection{La aparición de lo fantástico en las primeras novelas de Buzzati}

Si en Bàrnabo delle montagne Buzzati ya abría un resquicio por el que asomaba lo fantástico, con la referencia a unos pequeños espíritus del bosque, verdes, ligeros e inofensivos (2007: 22-23) y a los crujidos como lenguaje de los muebles (2007: 102), en Il segreto del Bosco Vecchio, el autor se asentaba con 
claridad en el ámbito de lo fantástico, poniendo en escena (como haría en 1943 Wenceslao Fernández Flórez en El bosque animado) a animales y vientos humanizados, a genios del bosque vinculados a los árboles centenarios, a una sombra independiente de su cuerpo y a cinco pesadillas de formas monstruosas (que anticiparán un pasaje de Poema a fumetti), junto a personajes humanos especiales que conocen el lenguaje de los pájaros.

\subsection{Lo fantástico en los cuentos de Buzzati}

Siendo importante, como se ve, la presencia de lo fantástico en la novela de Buzzati, es en los cuentos donde tiene mayor peso o se agranda. En la mayor parte de sus relatos, el autor plantea situaciones de apariencia intrascendente que se convierten, poco a poco o de improviso, por la aparición en ellas de algo contrario a la experiencia común, en extrañas, misteriosas, inquietantes o terroríficas, sin, por lo general, extremar las tintas y, en ocasiones, hasta matizadas o teñidas por el humor. Son varias las ocasiones, además, en que los narradores de sus relatos hacen referencia a las zonas oscuras o ambiguas de la experiencia humana que la ciencia no puede explicar ${ }^{1} \mathrm{y}$ algunas en las que convocan la intersección del mundo real y el de los fantasmas, como en «Asalto al gran convoy» o en «El burgués hechizado».

Los componentes de lo fantástico en estos cuentos son variados. En ocasiones se trata de animales y seres fantásticos («Monstruos modernos», «El colombre», «La matanza del dragón» o «El Coco»). En otras, son metamorfosis («Hoyo número dieciocho», «La niña abandonada», «La mujer con alas», «Pequeña Circe», «El escollo» o «La mariposita») y, como suele ser usual en el ámbito de lo fantástico, abundan los hechos extraordinarios. ${ }^{2}$

Pero lo más interesante en relación con Poema a fumetti y el descenso a los infiernos que narra es la importante presencia en estos relatos de las pos-

1. Así sucede en El secreto del Bosque Viejo (Buzzati, 2004: 109-110), en «Nadie me iba a creer» (Buzzati, 2010: 41) o en «Anécdotas de la ciudad» (Buzzati, 2010: 198).

2. Una gota a la que se oye subir los peldaños de una escalera de vecinos («La gota»); una chaqueta en cuyos bolsillos aparece el botín de robos o desastres («La chaqueta embrujada»); unas gafas que permiten ver a los viejos futuros en el cuerpo de los jóvenes actuales («Los viejos clandestinos»); las cajas que contienen los días perdidos («Soledades»); un coche viejo dotado de habla y sentimientos («Viejo coche»); un televisor que tiene la cualidad de funcionar solo cuando se habla de los interesados y de mostrarles la escena («El televisor sabio», en «Invenciones»); la superficie de un jardín que se modifica cada vez que muere una persona querida por el dueño («Los bultos del jardín»); la autopista en la que todos los coches son conducidos por la misma persona («Al volante», en «Pequeños misterios»); los maleficios de los dioses faraónicos despertados por la visita de un viejo rey a una excavación arqueológica y su diálogo con la estatua del dios Thot («El rey en Horm El-Hagar»); un hombre que posee el don y la maldición de la ubicuidad («El ubicuo»); una joven que va envejeciendo a medida que cae de un rascacielos desde el que se ha arrojado («Muchacha que se precipita»). 
trimerías católicas, de la muerte y del Más allá. Lo relativo a la religión es muy abundante en los textos de Buzzati, aunque no se trata, en todo caso, de una aproximación seria o reflexiva, sino de la utilización de un componente habitual en la sociedad italiana y en la vida de las gentes sobre las que escribe, tratado con ironía humorística. ${ }^{3}$ La muerte es también un componente constante en la narrativa de Buzzati y son muy pocos los relatos suyos en los que no está presente, de un modo u otro, ya sea como amenaza ominosa que el personaje siente a punto de cumplirse (por la enfermedad que labora sin descanso o por sentencia incomprensible de los otros), ya como realidad cumplida y con los personajes viviendo en el Más allá. ${ }^{4}$ En «Batalla nocturna en la Bienal de Venecia» Buzzati plantea la terrible perfección de lo creado, la ausencia de un mañana, de un tiempo suplementario, una vez la muerte se lleva al creador. En los relatos de Buzzati asoman también fantasmas cómicos o patéticos ${ }^{5}$ y algunos fantasmas trágicos, como el del joven soldado muerto que, acompañado por la Muerte en forma de oficial, hace una última visita a su madre («La capa»), o el fantasma «transparente», «convertido en sombra», del jefe de bandidos que se aleja hacia «el país de los bandoleros muertos» («El asalto al gran convoy»), o la muchacha con extraño parecido a la esposa muerta del protagonista que acude a una fiesta y atrae al marido viudo, quien comprobará que el lugar donde la ha dejado al acompañarla a casa es el cementerio («La sosias», en «Tres historias del Véneto»).

El Más allá es otro componente del ámbito fantástico que se insinúa en «Y sin embargo, llaman a la puerta» y que se describe en «Noche de invierno en Filadelfia» en el sueño que precede a la muerte del subteniente Muller,

3. Así, en «El platillo se posó», un cura se regocija al caer en la cuenta, en diálogo con dos extraterrestres, de que es mejor ser un humano pecador que un marciano perfecto; o en «El perro que ha visto a Dios», donde toda una comunidad se siente traspasada por los ojos del que creen el perro de un santo ermitaño muerto y evitan el pecado, o en «El fin del mundo», donde la aparición del puño de Dios anuncia el fin de los tiempos y provoca la angustia colectiva por confesarse y evitar la condenación eterna. 4. En «Delicadeza», Buzzati lleva a cabo una especie de teorización sobre cómo afrontar la muerte. En este relato, el director de una prisión, trata de convencer a un condenado a muerte de lo infundado de sus temores ante la inminencia de su ejecución, ya que - argumento de los estoicos-, una vez muerto, cesan todos los afectos, deseos y temores que le acuciaban cuando vivo; tampoco la duda sobre si hay otra vida después de esta es ningún problema: si la hay, no es malo morir, porque será una continuidad de la conocida; si no la hay, tampoco habrá conciencia de haber perdido la vida, por lo que, de un modo u otro, no habrá dolor. En consecuencia, no hay que temer a la muerte. La «delicadeza» del director termina de forma cínica y macabra.

5. Unos espíritus humanos encarnados en moscardones («Algunas indicaciones útiles»), el fantasma del violinista que aún conserva una cierta «solidez residual» y que es rechazado por todos sus amigos, cuando busca un lugar donde descansar («Los amigos»), el viejo pintor «afincado para la eternidad en los campos elíseos» que decide volver a la tierra para visitar la bienal de Venecia donde dos años después de su muerte le han dedicado una sala («Batalla nocturna en la Bienal de Venecia») o los agradables fantasmas, humanos y de osos, del castillo de la Roca Diabla de La famosa invasión de Sicilia por los osos. 
colgado de su paracaídas en la pared de una montaña con la inquietante similitud al mundo de los vivos que Buzzati empleará en Poema en imágenes (Buzzati, 2006: 371-372). El Cielo es imaginado justo encima de la Tierra, en el lugar donde orbitan tres naves espaciales lanzadas en 1958, con sus tripulantes muertos: «Ejércitos transparentes de Bienaventurados — finalmente lo sabemos- se deslizan cantando por encima de nuestras cabezas (iy nosotros que creíamos que Dante Alighieri se lo había inventado todo» («24 de marzo de 1958», 2006c: 334). La sensación que queda a los humanos es la de una frontera que les cierra el paso. El Cielo también es imaginado como unas casitas donde están los santos contemplando desde el balcón a Dios, que —como he dicho- es un mar y también un humo («Los santos»).

Dios es también un personaje en algunos cuentos de Buzzati. Aparece en la creación, tentado por un ángel inventor para que cree al hombre ( «La creación») y en el fin del mundo sin forma definida («El fin del mundo», 2006c: 209); Dios es una presencia que llena la catedral o flota sobre los campos nevados («Cuento de navidad») o como el mar, al que dan los balcones de las casitas donde viven los santos, y también el humo del fuego con que preparan la sopa. («Los santos»). Y junto a Dios, el Diablo, también asoma con distintas formas en estos relatos: los diablos, negros con aspecto de bailarines y largas colas, que se llevan las almas de los jóvenes carbonizados en un coche («Incidentes del camino»), el diablo Iblis, el Ángel de la Muerte, con apariencia de joven negro hermoso e imponente que acude a llevarse a Einstein («Cita con Einstein»), el diablo que adopta la forma de un confesor para llevar al vicio a un santo ermitaño («El ermitaño»), el demonio que se aparece a la muchacha enamorada que sufre y le promete que le dará al enamorado, con la condición de que nunca lo traicione, ante lo que la muchacha se ve obligada a renunciar («Mosaico»), «el sastre de la mala suerte» que confecciona la chaqueta embrujada en cuyos bolsillos aparece el dinero del crimen, el Schiassi de «El ascensor», «un señor al que echaría unos cincuenta y cinco años, un tanto deteriorado, ni gordo ni delgado, prácticamente calvo, de rasgos marcados e inteligentes» (2008: 176), o el Onofrio de «Garaje Erebus» que esconde su identidad bajo el disfraz de mecánico y a quien el narrador intenta vender su alma tras una vida proba, pero ya demasiado tarde.

El infierno tiene diferentes entidades y manifestaciones en la obra de Buzzati. En «Viaje a los infiernos del siglo», estos infiernos, como planteó Sartre, están aquí: en el estrés del ambicioso, en la niñez desgraciada, en la soledad del rico, en la muerte del niño atropellado, en el asesino, en el estúpido al 
volante, en los viejos arrojados a la calle, en la especulación inmobiliaria. ${ }^{6}$ En «Mosaico» el infierno es el tradicional, con su desorden y suciedad. Pero es en «Extraños nuevos amigos», donde Buzzati anticipa el Más allá de Poema a fumetti y concibe un infierno cuya apariencia externa es similar al mundo de los vivos. $^{7}$ Esta ciudad extrañada tiene otro atisbo en «La ciudad personal», la ciudad que cada uno crea para sí, en la cual el narrador confiesa sentirse mortalmente solo y consciente de la inutilidad de su vida. ${ }^{8}$

\subsection{Il deserto dei Tartari}

Algunos de estos componentes temáticos están también en su novela más importante, Il deserto dei Tartari. ${ }^{9}$ En ella, Buzzati personificaba la desorientación vital y afectiva del hombre del siglo xx en su protagonista, Giovanni Drogo, joven oficial que consume su vida en una fortaleza militar en la espera inútil de la llegada de los tártaros, mientras el tiempo pasa vertiginoso. Es inevitable pensar en El castillo, de Kafka, y en la parábola hiriente y angustiosa de la tenacidad absurda y obsesiva del agrimensor $\mathrm{K}$, condenado al fracaso de sus expectativas, como un nuevo Sísifo, y a la muerte. La vida como una broma absurda. Todo el relato tiene la consistente inconsistencia de los sueños o los mundos fantásticos, como el Castroforte del Baralla de La saga-fuga de J.B., de Torrente Ballester, y, en otro sentido, del sanatorio Berghoff de La montaña mágica: un lugar y una vida singulares, similares a lo «normal», pero con un evidente halo de extrañeza, alejados de una realidad donde la vida fluye, a pesar de estar cerca de ella (a dos días de caballo de la ciudad), mientras ellos esperan sin sentido y con una resignación angustiosa a que los reciba el señor del castillo o se declare la guerra y con

6. Un planteamiento similar se da en la novela de Antonio Fontana, Plano detallado del infierno (2007). 7. En este relato un hombre, tras morir, se encuentra «en una ciudad maravillosa hecha de palacios suntuosos, calles amplias y regulares, jardines, prósperos negocios, lujosos automóviles, cines y teatros, gente bien alimentada y elegante, sol brillante, todo bellísimo». Cree que es el paraíso, aunque le llaman la atención la ausencia de iglesias y la reticencia de su guía, cuando pregunta por Dios. Un señor mayor al que le presentan sostiene que allí se ha de estar contento por fuerza, porque «todo aquello que nos hacía sufrir allá, ahora ha desaparecido». No existe el dolor ni, por tanto, el miedo, ni sueños ni deseos, ni nostalgias ni remordimientos, ni la muerte: «Aquí pasa lentamente el tiempo, hoy es igual a ayer, mañana igual a hoy, nada malo nos puede suceder». La conclusión es clara y aterradora: está en el infierno. 8. «En la inmensa ciudad que ninguno de ustedes conoce ni jamás conocerá, en la ciudad hecha de mi misma vida (jardines palacios adioses gasolineras hospitales primaveras cuarteles pórticos Navidades estaciones de tren estatuas amores) ¡Dios mío, qué solo estoy! Unos pasos resuenan misteriosos de una casa a otra repitiendo: ¿Qué haces? ¿Qué quieres? ¿No te das cuenta de que todo es inútil?» (Buzzati, 2006c: 447)

9. Aunque, como señala con acierto Rosalba Campra, es «la ausencia de toda motivación» la que crea «por sí sola las condiciones de lo fantástico». Algo que ejemplifica en particular con este relato de Buzzati. (Campra, 2001: 179). Un aspecto cercano a este sería la falta de asombro con que el narrador y los personajes acogen la transformación de Gregor Samsa en La metamorfosis, de Kafka. (Reisz, 2001: 218). 
ello sus vidas puedan alcanzar alguna justificación, sin conseguirlo, sin poder impedir que sus vidas acaben de forma absurda y miserable.

En la novela se concitan el sueño funesto y la muerte ${ }^{10}$ y también el Más allá con la idea de paso del umbral que será clave en Poema a fumetti. ${ }^{11}$ La extrañeza y desolación del mundo de la Fortaleza son un anticipo de las que experimentará el protagonista de Poema a fumetti en su descenso a los infiernos, ${ }^{12}$ lo mismo que la soledad radical del hombre en el dolor ${ }^{13}$ y la presencia obsesiva del tiempo que hace y deshace la vida del hombre, sordo a los deseos de que se detenga, a los esfuerzos por resistir su corriente (como ocurrirá en la separación de Eura y Orfi en Poema a fumetti), estancado en el momento previo a la muerte de Drogo, como se estancará hasta desaparecer en el Más allá del Poema, mientras los relojes corren inútilmente (2006a: 266).

\section{Poema a Fumetti}

\subsection{El descenso a los infiernos}

El descenso a los infiernos, ya sea como «realidad» religiosa, ya como metáfora psicológica o como mero lugar de la aventura, ${ }^{14}$ está presente en

10. «En el sueño la presencia de semejantes criaturas, nunca vistas en el mundo [apariencias frágiles, semejantes a hadas] no asombraban a Giovanni» (2006a: 95). Estas criaturas danzan ante la ventana de su amigo Angostina y Giovanni tiene envidia, hasta que comprende que el palanquín que han traído es una carroza fúnebre que se llevará a su amigo para siempre.

11. «Creyó [el soldado Prosdocimo] estar muerto y que Dios lo había perdonado. Pensó que se encontraba en el mundo del más allá, aparentemente idéntico al nuestro, con la diferencia de que las cosas hermosas se ajustan a los deseos apropiados y, después de haberlos satisfecho, nos sentimos con el alma en paz» (2006a: 127). Y el propio Drogo, cuando concibe ilusionado que la batalla contra la muerte, con dignidad de soldado, puede ser la justificación de su vida fracasada, siente que «se esfumaron los antiguos terrores, se desplomaron las pesadillas, la muerte perdió su horripilante rostro y se convirtió en algo simple y conforme a la naturaleza. (...) El comandante Giovanni Drogo, consumido por la enfermedad y los años, pobre hombre hizo fuerza contra el inmenso portal negro y se dio cuenta de que los batientes cedían y abrían paso a la luz» (2006a: 268). Y, mortificado por tener que morir con el cuerpo envejecido y macilento por la enfermedad, llega a concebir un regreso de la muerte: «Pero a saber si, traspasado el negro umbral, no podría también él regresar como en tiempos, no hermoso (porque nunca lo había sido), pero fresco de juventud» (2006a: 269).

12. «Las paredes desnudas y húmedas, el silencio, la desolación de las luces: todos allí dentro parecían haber olvidado que en alguna parte del mundo existían flores, mujeres risueñas, casas alegres y hospitales. Todo allí dentro era una renuncia, pero ¿para quién? ¿En pro de qué misterioso bien?» (2006a: $30)$; «Le pareció encontrarse entre hombres de otra raza, en tierra extranjera, un mundo duro e ingrato» (2006a: 54).

13. «Precisamente por aquel tiempo se dio cuenta Drogo de que los hombres, aun cuando se estimen, permanecen siempre distantes, de que, si uno sufre, el dolor es totalmente suyo, ningún otro puede hacerse cargo ni siquiera de una parte mínima, de que, si uno sufre, no por ello sienten los otros dolor, aun cuando haya un gran amor por medio, y eso provoca la soledad de la vida.» (2006a: 226).

14. Baste recordar los descensos del propio Orfeo, Hércules, Ulises (aunque en este caso son las almas las que acuden a él, convocadas por un sacrificio), Osiris y Horus, Cristo, Mahoma, algunos héroes artúricos (como Gauvain o Guingamor) o Dante y, en la actualidad videojuegos como el que protagoniza el 
numerosos textos de todos los tiempos y lugares. Jung sostiene que se trata de un universal de la imaginación humana y no cabe duda de que en el fondo de todas estas estas experiencias subyace el enfrentamiento imaginado del hombre con su muerte y la esperanza de la resurrección. ${ }^{15}$

Mircea Eliade considera que el Mundo de los Muertos fue creado, para el pensamiento primitivo, por el alma de la divinidad primordial (una muchacha, un niño, un hombre), cuando su cuerpo fue despedazado en un sacrificio ritual originario que iba a permitir el crecimiento de los cereales, tubérculos y frutales, brotando de su cuerpo (como se ve en alguna representación de Osiris yacente). ${ }^{16}$ Los rituales de iniciación en los que el héroe desciende al abismo y se enfrenta a un monstruo (el bautismo sería una variante de ellos) reviven esa experiencia primordial y renuevan el compromiso con los dioses y con la renovación de la vida (Eliade, 1998: 101). El mito de Orfeo y Eurídice responde a este arquetipo.

\subsection{Tradición y novedad en la reescritura del mito}

No hay ironía ni subversión del mito clásico en el relato de Buzzati, sino un aprovechamiento personal de lo recibido de la tradición. Su texto actualiza y relocaliza el mito trayéndolo al Milán de la actualidad, que será tanto la ciudad de los vivos como de los muertos, tomando del mito solo la historia central del fallido rescate de Eurídice del Hades (no la muerte de Orfeo a manos de las bacantes) y cambiando algunos aspectos del argumento clásico de Ovidio y Virgilio: los protagonistas no están casados, Eura no muere por la mordedura de una serpiente, al escapar de Aristeo, las criaturas y dioses infernales son sustituidos por un diablo custodio en forma de chaqueta, Orfi no encuentra de inmediato a Eura, sino que lleva a cabo una búsqueda por diferentes lugares del infierno, adquieren protagonismo hermosas muchachas desnudas que tratan de apartar a Orfi de su empresa, Eura considera inútil el conmovedor esfuerzo de su amado, el plazo temporal para el rescate sustituye al precepto de Proserpina de no volver la cabeza y Orfi, al final, duda de la experiencia que ha vivido.

propio Dante (irreconocible) o Silent Hill 2 HD, donde una esposa muerta exige al marido que la busque en una ciudad espectral.

15. Que también aparece en otros mitos poderosos como el del vampiro o el de Frankenstein (Roas, 2013: 92).

16. «Este primer asesinato cambió radicalmente el modo de ser de la existencia humana. La inmolación del ser divino instauró tanto la necesidad de la alimentación como la fatalidad de la muerte, y como secuela, la sexualidad, único medio de asegurar la continuidad de la vida. El cuerpo de la divinidad inmolada se transformó en alimento; su alma descendió bajo tierra, donde fundó el País de los Muertos» (Eliade, 1998: 76). 


\subsection{Argumento de un viaje fantástico al Más allá}

Buzzati estructura su relato en cuatro partes precedidas de un título orientativo sobre su contenido.

\section{El secreto de Vía Saterna}

En la ciudad vieja de Milan hay una mansión misteriosa sobre la que corren leyendas inquietantes de sexo y crimen (Figura 1). ${ }^{17}$ Enfrente de una pequeña puerta del muro perimetral de esa mansión está la casa de Orfi, hijo de una noble familia venida a menos, músico de éxito ${ }^{18}$ en la sala Polypus que hechiza a sus seguidores/as con canciones como «Las brujas de la ciudad»y sus poderes. Una noche ve a su amada Eura atravesar la puerta del muro de la casa misteriosa (Figura 2) y, aunque se niega a creer lo que ha visto, a la mañana siguiente un misterioso personaje le corrobora que los numerosos cortejos fúnebres que recorren la ciudad son, todos ellos, debidos a la muerte de la muchacha que él debía conocer. Por la noche, abrazado a su guitarra (que le da seguridad), Orfi consigue atravesar la puerta de la muerte cantando

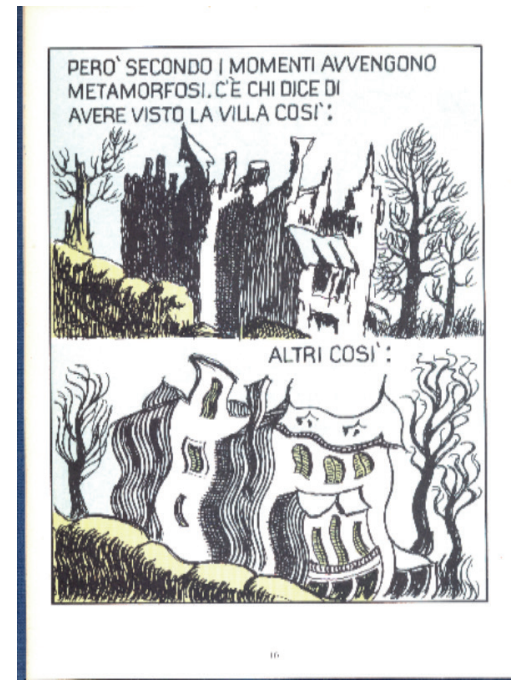

Figura 1

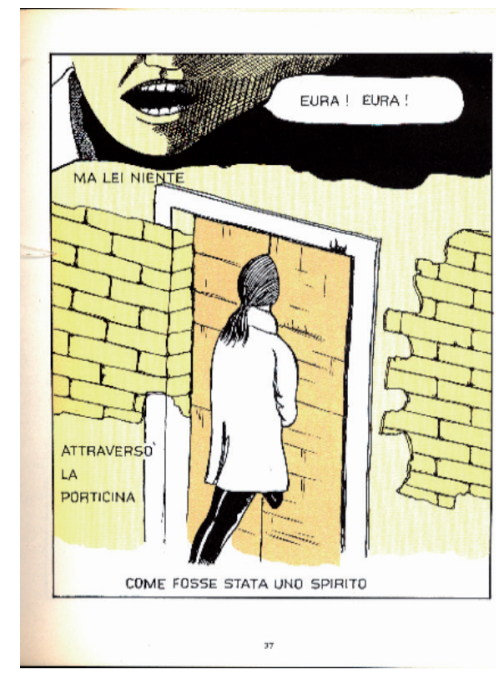

Figura 2

17. El lector encontrará las ilustraciones al final del artículo.

18. El protagonista, joven y artista, viene dado por el mito pero, de forma reveladora, va a ser la pauta o a coincidir con un buen número de protagonistas del género fantástico similares, vinculados con el principio del placer (Bellemin-Noël, 2001: 122). 
una canción de llamada y accede a un vestíbulo donde una seductora y enigmática mujer le aconseja pensar bien lo que va a hacer y Orfi se lanza escaleras abajo, mientras el narrador verbal lo anima pero también lo interroga sobre el enigma que encontrará y la dificultad para volver.

\section{Explicación del Más allá}

La chica que lo guía enflaquece al entrar ambos en el «País de la famosa anciana señora», «la que destruye los placeres», pero no cambia la ciudad que Orfi ve al otro lado de un gran ventanal, cuando el Amo de ese lugar, un diablo custodio (representado por una chaqueta vacía) (Figura 3) se aplica a derribar viejos tópicos de los vivos, como el del Valle de Josafat: en este País cada muerto accede con su mundo, el tiempo está detenido, aunque siguen los actos de la vida y los ahora ya inmortales (un poco transparentes, eso sí) no conocen más la esperanza del dolor y de la muerte y padecen la enfermedad de la añoranza de esos miedos y esas angustias, de las zozobras del deseo erótico, todo lo que es «la sal de la vida» y que se debe a la muerte, «don sabio de Dios». Orfi pide al Diablo custodio que le indique dónde está Eura y rechaza el ofrecimiento erótico de cinco muchachas seductoras.

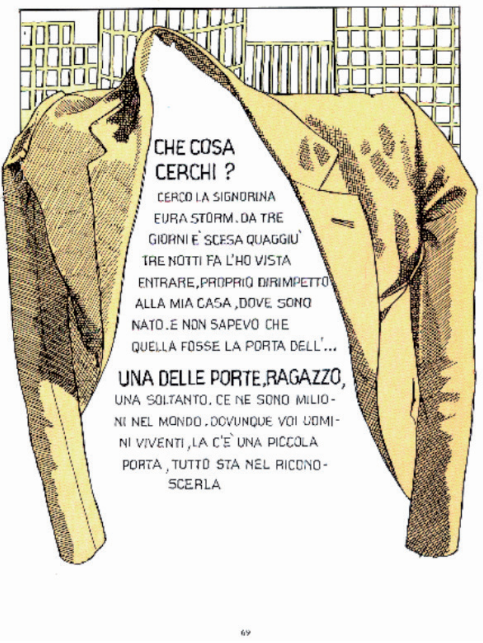

Figura 3 
Las canciones de Orfi

El Diablo le ofrece indicarle el paradero de Eura si antes Orfi (aunque esté prohibido hacerlo) canta algunas canciones sobre las cosas perdidas por los muertos de las que han estado hablando. Orfi canta entonces, para una multitud de muertos en marcha, sobre las inquietudes, los temores, las pesadillas, el dolor, la soledad y la asechanza continua de la muerte. La muchedumbre, ahora detenida, exige que siga cantando y el joven canta historias en las que anida la muerte: la de la joven Onizia hechizada por una cara espectral al otro lado de la ventana, la del solitario tocado y transformado por Chopin, la del viandante que siente algo a su espalda pero no encuentra nada al volverse, la de los nueve caballeros que una noche estrellan su carruaje demoníaco contra el palacio de la amada de uno de ellos, la del guardabarrera que cada noche espera el paso del expreso fantasma con sus pasajeros muertos, la de la muchacha desnuda atacada y aniquilada por una sombra, la historia de las melusinas que tienen contacto con los muertos y, sobre todo, la historia del amor y del deseo sexual amenazados por la muerte en forma de imprecisa llamada a la puerta, de una anciana señora que te mira al pasar cuando la amante no llega y quizá no llegue nunca, latente en el cansancio de la carne satisfecha, en la «petite mort» del orgasmo (Figura 4). Orfi termina con la historia de Dios en sus múltiples facetas (el infierno, el remordimiento, las desesperaciones, el que se acerca en silencio en la hora de la muerte). El Diablo

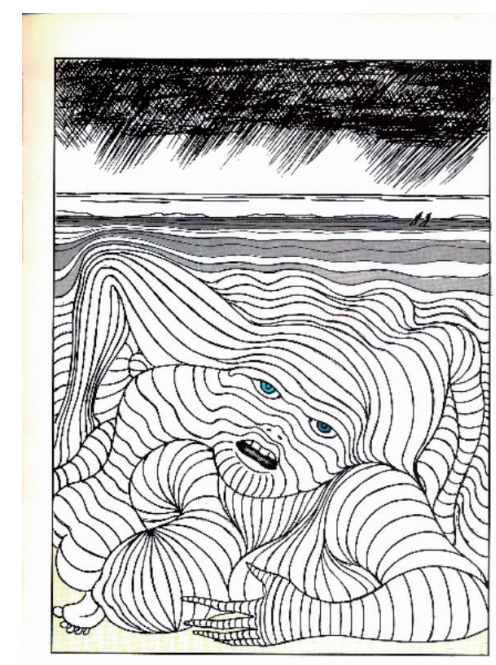

Figura 4 
custodio concede entonces veinticuatro horas a Orfi para que encuentre a Eura y el muchacho sigue bajando por la escalera.

\section{Eura reencontrada}

Orfi llama a Eura, sin dejarse desanimar por la multitud de muertos que halla, ni seducir por «muchachas desvergonzadas». Una de ellas le sugiere que busque en el Registro civil, donde otra muchacha desnuda y procaz le informa de que Eura se ha ido ya o está a punto de partir. Orfi corre entonces a la estación de donde parten los trenes de la muerte sin que se sepa su destino ni tampoco si, en verdad, partirán o no. De improviso, Orfi y Eura se ven y se abrazan emocionados pero Eura (cuyo cuerpo está desnudo y frío) es escéptica respecto a su rescate: aquí no valen las canciones en las que fía su amado: «Aquí», dice la muchacha, «Manda la Gran Ley. No creas en viejos cuentos». El tiempo corre en el reloj de Orfi que insiste, que tira del brazo de su amada, pero ella intenta disuadirlo con una nueva referencia al mito del que ellos son reescritura: «Ya te lo he dicho, cielo. Es inútil. No puedo acompañarte allí arriba. Pobre cuento de Orfeo. Aun cuando no vuelvas la vista atrás, igual no te serviría.» El tiempo del plazo (gran motivo romántico) expira y una fuerza irresistible rompe el abrazo de los amantes y sus manos enlazadas y se lleva (Figura 5) a Orfi que vuelve a encontrarse delante de la puerta de la mansión misteriosa ante el mismo hombre con el que habló antes de entrar. Este le

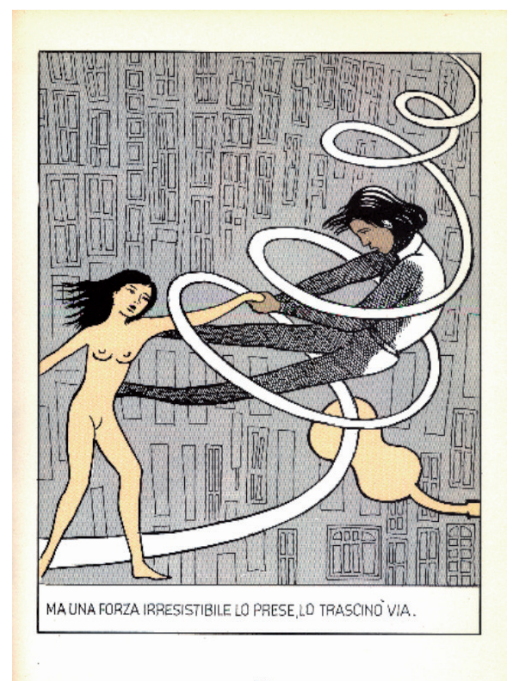

Figura 5 
aconseja que no se atormente por lo que ha experimentado, porque todo ha sido un sueño; por un instante, le permite ver la realidad de los cuerpos de los muertos en sus sepulturas (el de Eura entre ellos), esperando la nada. Pero Orfi se da cuenta de que aprieta algo en su mano y descubre que se trata del anillo de Eura, arrancado del dedo de la muchacha al ser separados. Pregunta al hombre misterioso por este fenómeno inexplicable, pero su interlocutor ha desaparecido. En ese momento se arremolinan las almas en pena en la tormenta, los últimos reyes de los cuentos se dirigen al exilio, «y en el desierto de Kalahari las nubes torreadas de eternidad pasaban lentamente».

\subsection{De la mitología a lo fantástico moderno}

La mitología plantea una interesante cuestión a una teoría de lo fantástico. ${ }^{19}$ Como creencia religiosa, los hechos sobrenaturales de la mitología poseerían el estatuto de las cosas reales (en verdad, serían las únicas cosas reales) o, al menos (como parte de una «tradición mítica aún viva», de lo «posible según lo relativamente verosímil»; Reisz, 2001: 196-197), mientras que, desaparecida esa creencia (García Gual, 2008: 31), pasarían a ser ficcionales, imaginarios o ilusorios y, con mucha frecuencia, fantásticos, aunque siga palpitando en ellos algo del sentido humano profundo que condensaron en su momento. Para la fe religiosa no es decisivo que la razón pueda o no explicar las «verdades» que caen bajo su jurisdicción; sencillamente, existen y son (han de ser) creídas. Lo ficcional tiene otro estatuto que ni siquiera roza el de los hechos sobrenaturales de este tipo. ${ }^{20}$ La resurrección de Cristo, por ejemplo, es para el cristiano «verdad de fe», no un hecho ficticio.

El relato del mito clásico aportado por Ovidio y Virgilio, falto de cualquier momento de duda por parte de los protagonistas (y de su lector implícito y, algo más dudoso, por parte de sus lectores reales) ${ }^{21}$ sobre la

19. Irene Bessière sostiene que lo fantástico: «no es más que una de las vías de la imaginación, cuya fenomenología semántica nace a la vez de la mitología, de lo religioso, de la psicología normal y patológica» y que «el relato fantástico surge del cuento maravilloso» (2001: 84 y 93). Por su parte, Susana Reisz distingue las variantes de lo sobrenatural moldeadas por las religiones de aquellas que no lo están y pertenecen, por tanto a lo fantástico (Reisz, 2002: 48, en Anyó, 2013: 45).

20. Como señala Sergi Viciana: «Si aceptamos que la realidad es un constructo mental, entonces lo que es posible o imposible depende de nuestro sistema de creencias para interpretar la realidad. Los milagros no cuestionan el universo de un creyente, porque en su sistema de creencias son posibles. En el sistema de creencias del vudú los zombis son algo real y posible.» (2013: 116).

21. Cuando se fecha la aparición del género fantástico a mediados del siglo XVIII en Occidente (1764, Horace Walpole, El castillo de Otranto), tengo la duda de si no es necesario revisar con detenimiento y precisión la concepción de la realidad de siglos y civilizaciones anteriores. Afirmaciones como «puesto que hasta ese momento lo sobrenatural pertenecía, hablando en términos generales, al horizonte de expectativas del lector» (Roas, 2001: 21), chocan contra lo aportado por la historia de las religiones 
realidad de la experiencia que viven, se sitúa en el ámbito de lo religioso-maravilloso. Pero el relato de Buzzati cambia de ámbito y de estatuto, porque sí presenta un conflicto entre la experiencia del protagonista (y la del lector implícito y, presuntamente, la del lector real $)^{22}$ en cuanto a la aparición de lo sobrenatural en la vida cotidiana. El mito ha abandonado el ámbito de lo religioso y, además, se ha reorientado hacia lo fantástico tradicional. Reelaboraciones o transcodificaciones que se dan también en otros autores como Nodier o Bécquer, en el ámbito del cristianismo y sus leyendas (Roas, 2001: 14).

El relato de Buzzati ofrece varios momentos de incertidumbre en la actuación de su protagonista masculino sobre si lo que ve y vive es posible o imposible, clave de lo fantástico (Reisz, 2001: 195; Roas, 2011: 263). ${ }^{23}$ El primero se produce cuando Orfi ve a Eura atravesar la puerta de la mansión misteriosa y se niega a creer lo que ha visto. El segundo se da cuando constata que el Más allá no responde a la iconografía asumida por la tradición. Y el tercero se da hacia el final, cuando Orfi duda de si todo habrá sido un sueño (ámbito de lo fantástico-maravilloso) y encuentra confirmación de lo real de su peripecia en el anillo de Eura que ha quedado en su mano al ser separados dramáticamente por una fuerza irresistible, cuando acaba el plazo concedido para el rescate (Figura 6). El protagonista ya no puede dudar y se instala, por tanto, en el ámbito de lo que Todorov denomina lo «maravilloso puro» (1982: 69-71): hay vida después de la muerte, el Más allá existe y él ha fracasado en el intento de rescatar a su amada.

donde se hace hincapié en la credulidad del vulgo, la incredulidad de los cultos (incluidos numerosos sacerdotes) y el aprovechamiento que de las creencias hacen los políticos.

22. La importancia de la actitud y reacción del lector ante este tipo de relatos es grande y evidente, como pone de relieve la crítica, pero, al mismo, tiempo es muy compleja. El lector real debe, por supuesto, admitir el pacto de ficción que se le ofrece (que no es poco) pero, además, debe confrontar su concepción de la realidad con la que se le ofrece en el relato. Y lo curioso en este caso es que esa concepción o su consistencia puede variar de la mañana a la noche (a la lectura nocturna, quiero decir) y depender de condiciones ambientales, como estar solo o acompañado. Menos problemática veo la posibilidad de que el lector admita la irrupción de lo sobrenatural en su mundo, porque bastará que su concepción de la realidad no excluya de forma tajante, a priori, esa contingencia. Por otro lado, más allá del narrador y del lector puede hallarse el texto, como bien señala Susana Reisz: «Que los personajes no cuestionen su propia norma ni, en última instancia, su propia noción de realidad, no implica que el texto mismo no la cuestione» (Reisz, 2001: 220). Y aún habría que tener una precaución más, como bien advierte Teodosio Fernández: «un creyente puede estar seguro de la posibilidad de los milagros o de la existencia de los demonios, pero no dejará de relacionar eso con lo sobrenatural, con una dimensión que no es la suya, con un universo misterioso en el que se puede creer pero que no se puede razonar» (2001: 294).

23. Estamos, pues, ante una realización de lo fantástico tradicional, porque, además del asombro (que no lo hay en relatos como La metamorfosis, de Kafka; Reisz, 2001: 218), se prescinde de la condición manifiesta del fantástico contemporáneo (en realidad, presente ya en los comienzos del pensamiento religioso) de que habla Roas: «la irrupción de lo anormal en un mundo de apariencia normal, pero no para demostrar la evidencia de lo sobrenatural, sino para postular la posible anormalidad de la realidad, lo que también impresiona terriblemente al lector» (Roas, 2001: 37). 


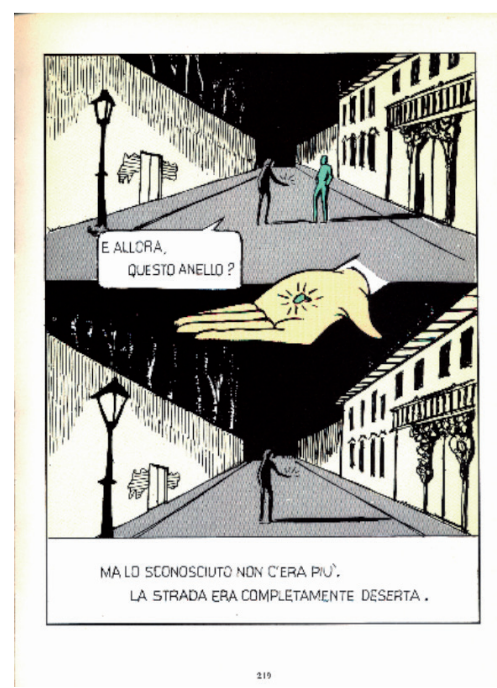

Figura 6

El relato de Buzzati (con la referencia a la mansión siniestra y sus leyendas y la canción de las brujas), tiene un comienzo propio de los cuentos de miedo que pretende crear un clima favorable a la importante (extremada) subversión de las leyes de la realidad que acaecerá luego, con el paso del umbral de Eura y Orfi y el descenso al Más allá. El paso del umbral es un topos o mitema esencial en los mitos del descenso a los abismos (García, 2013: 27) y, en realidad, una de las condiciones del fantástico. ${ }^{24}$ Eura atraviesa el umbral del Más allá, desmaterializándose, reproduciendo con ello, además, «la tópica imagen del fantasma atravesando paredes» (Roas, 2001: 9). Hablando de lo siniestro, sostiene Freud (1998) que es la angustia ante la muerte y sus mensajeros la causante del miedo que provoca ese sentimiento.

Pero el relato de Buzzati no busca provocar miedo ni con la palabra ni con la imagen, sino curiosidad y, quizás, como mucho, inquietud. De hecho, como he relatado más arriba, los miedos y sus causas aparecen en Poema como una referencia metanarrativa, en la canción de Orfi a los muertos, quienes ya carecen de cualquier temor, para su desgracia.

El Más allá de Buzzati tiene más del Hades griego o el Sheol judaico (lugar neutro después de la muerte) que del lugar de castigo eterno propio del

24. «Cuando se afirma que el mundo obedece a unas leyes donde la razón es la única posibilidad, y se relegan los fantasmas y los magos a la irracionalidad, definiendo dos ámbitos muy claros, en ese momento surge la posibilidad de lo fantástico. Esta afirmación se confirma al ver cómo esto "se produce cuando uno de los ámbitos, transgrediendo el límite, invade al otro para perturbarlo, negarlo, tacharlo o aniquilarlo" (Bravo, 1993: 36)» (Alarcón, 2013: 76). 
cristianismo, aunque sí sea ominosa la falta de vida y de vitalidad de sus moradores y su añoranza.

El Más allá del Poema es un lugar similar al mundo de los vivos, alejado, por tanto, de la tradición pictórica del mito ${ }^{25}$ y modernizado. Hay una continuidad espacial entre ambos mundos que se agrieta por el extrañamiento que producen los espacios duplicados allí donde no se los espera encontrar, ${ }^{26}$ y, sobre todo, por la representación del diablo como un gabán dotado de movimiento y palabra, rechazando la figura grotesca y aterradora de los diablos de la tradición pictórica y literaria. ${ }^{27}$

La segunda condición más llamativa de este Más allá de Poema es la abundancia de muchachas jóvenes desnudas que erotizan el relato (Figura 7). La vinculación entre el eros y el tánatos es un lugar común desde Freud, y Todorov, en su estela, considera el relato fantástico, en particular, como una forma de expresar deseos inconscientes reprimidos. Dentro de los que el investigador búlgaro denomina «temas del tú» incluye lo relativo al deseo sexual vinculado con la muerte, a la necrofilia y a la novia muerta, y sostiene que «las preocupaciones relativas a la muerte, a la vida después de la muerte, a los cadáveres y al vampirismo están ligadas al tema del amor» (Todorov, 1982: 165-166).

Pero el relato es erótico — supongo- para el lector, pero no para el protagonista del relato, que no manifiesta sentirse atraído por las numerosas mujeres sensuales que se le ofrecen a la vista o se le insinúan abiertamente. El rescate de Eura es la obsesión de Orfi y nada consigue apartarlo de su búsqueda. La sexualidad tampoco juega un papel explícito en la relación de los dos

25. Y también de otros cómics posteriores, como el de Neil Gaiman, The Song of Orpheus, que recrea el Hades a la manera tradicional, recargando las tintas de lo terrorífico, sobrepasando con creces a Dante y sus ilustradores (sobre todo en el «Prólogo» a Estación de nieblas).

26. Algo parecido se producirá más tarde en el relato «Dos reinos», de Liudmila Petrushévskaia (dentro de Érase una vez una mujer que quería matar al bebé de su vecina, 2011: 145-154). Cuenta el relato la forma progresiva en que una mujer joven toma conciencia de que está muerta y de que se halla en el reino de los muertos. Hay extrañeza, primero, por la aparición de un extraño joven barbudo, Vasia, que se casa con ella y se la lleva de la mesa de operaciones de la unidad de cuidados especiales donde yacía; después hace un extraño vuelo en avión hasta una no menos extraña y maravillosa ciudad separada en dos por un río que ella no puede franquear. Le entristece la añoranza de su madre y el hijo pequeño que deja atrás y le duele no poder comunicarse con ellos ni participar de la vida de la otra parte de la ciudad, que ve alegre y llena de vida. Hasta que poco a poco cae en la cuenta de que lo que le ocurre es que está muerta.

27. «Existe una larga tradición de desmitificación humorística de los demonios, cancerberos, infiernos y demás realidades ansiogénicas que se remonta, como mínimo, a Epicuro y sus epístolas, para continuar con Lucrecio y su De rerum natura, Luciano de Samosata y sus Diálogos de los muertos, Erasmo y su Preparación para la muerte, Rabelais y su Gargantúa y Pantagruel, Montaigne y sus Ensayos, hasta llegar a Borges y sus burlas de los castigos eternos que los hombres pretenciosamente consideran merecer» (Castany, 2013: 141-142). 


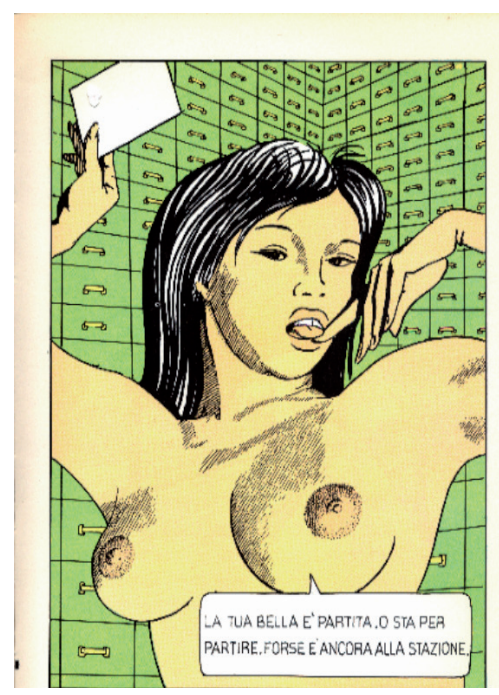

Figura 7

jóvenes. Nada sabemos al respecto de su historia anterior y, siendo llamativa la diferencia del aspecto de Eura cuando cruza el umbral (pelo recogido en una coleta, abrigo sin forma, gesto recogido) y cuando es hallada por Orfi (desnuda, lozana, el gesto radiante, pelo suelto), la actitud de la muchacha en esa situación no es erótica, sino cariñosa. El deseo y el placer están excluidos del encuentro de los jóvenes, lo mismo que el morbo, porque se hallan en el dominio de la muerte arrebatadora, aniquiladora.

\subsection{Un relato postmoderno a fumetti}

Poema a fumetti es, como va viéndose, un producto postmoderno, con su mezcla de ámbitos, su reescritura del mito, adelgazado de su alto espesor significativo (García Alonso y Prat Ferrer, 2007), las citas de textos propios y ajenos ${ }^{28}$ la síntesis personal de estilos (como la pintura metafísica de De Chirico y el surrealismo de Dalí, Chagall y Magritte, unidos al pop-art italiano y a los desnudos sensuales de mujeres jóvenes, propios de las revistas eróticas populares) y los cambios de estilo para representar y transmitir distintos contenidos o estados de ánimo y sentimientos de sus personajes (Palmieri, 2011).

Dino Buzzati optó por contar esta historia en cómic, un vehículo de la

28. Buzzati colocó al principio de Poema a fumetti una nota de agradecimiento en la que nombra a pintores como Dalí o Caspar David Friedrich o cineastas como Murnau o Fellini, con las páginas específicas en las que los cita $\mathrm{u}$ homenajea. 
«baja cultura», como un episodio o una manifestación más de su capacidad creativa y gusto para la pintura, la literatura y los relatos mixtos de ambos. Buzzati, en efecto, se consideraba tanto un pintor (su verdadero oficio, decía) como un narrador literario (su afición) y declaraba que lo sustancial era contar una historia y no el medio con que se hacía (Buzzati, 1968). ${ }^{29}$ Esta confluencia «natural» en él de lo narrativo literario y visual es lo que explica que el autor hiciera algo más parecido a una novela gráfica (así se subtitula ahora en la traducción española) que a un cómic tradicional. ${ }^{30}$

Como medio de narración verbo-icónico, el cómic presta algunas peculiaridades al relato fantástico.

Considera Todorov, por ejemplo, que el narrador representado (el personaje narrador) conviene al género fantástico porque «facilita la necesaria identificación del lector con los personajes» (Todorov, 1982: 105), pero en Poema a fumetti, la narración visual no es adjudicable al protagonista sino que se realiza, como es usual en el cómic (y en el cine), mediante un narrador impersonal, extradiegético, lo que da al relato, en principio, la consistencia de lo real objetivo. No obstante, la propuesta de Buzzati es la de animar al lector a compartir el punto de vista del protagonista y a «subjetivizar» así, de algún modo, el relato. ${ }^{31}$

Junto a ello, se comprueba cómo la narración mediante imágenes (estáticas), propia del cómic, afecta a la condición de lo narrado en un relato fantástico (entre otras cosas) en la medida en que, primero, dota de realidad a lo que no existe como referente $y$, después, en que cambia la imprecisión del lenguaje (tan importante para los efectos de sugerencia del fantástico) por la

29. Ya había realizado en 1945 La famosa invasione degli orsi en Sicilia (cuento ilustrado escrito para sus sobrinos), y dos años después del Poema a fumetti hizo I miracoli di Val Morel, treinta y una imágenes con narración escrita que ofrecen milagros imaginarios atribuidos a santa Rita de Casia. En lenguaje de cómic desarrolló mediante una macroviñeta historias como «Toc, toc» (1957, que autocitará en Poema a fumetti), «Il delitto di Via Calumi» (1962), «La ragazza che precipita» (1962, «traduzione» de su cuento con ese título), «La vampira» (1964), «I misteri dei condomini» (1965) o «La casa dei misteri “Alle cinque"» (1965, cuyos gritos y gemidos avanzan los de la mansión de Vía Saterna de Poema a fumetti). A estas manifestaciones hay que añadir los numerosos cuadros pintados por el autor, algunos de los cuales se transparentan o reproducen autocitados en Poema, como «La Giacca» (1967), "Santa ingenuitá» (1966) o «Grande cane in piazza in una giornata di sole» (1969).

30. Texto «reacio a la codificación más estrecha y canónica», señala Pozo (2009: 67); de «cómic sui generis» lo califica González (2010: 197). Sobre la novela gráfica es útil consultar Trabado (2013).

31. Como ocurre también, por ejemplo, en numerosas películas, teleseries y algún videojuego como Silent Hill 2 HD. Dice Lluís Anyó sobre la sorpresa final de este videojuego (en el que todo ha sido una pesadilla del protagonista) que: «El protagonista no es fiable, narrativamente hablando, en tanto que su punto de vista — que nosotros como jugador[es] hemos aceptado y compartido durante el juego- se corresponde con el de una mente trastornada, que vive una realidad distorsionada o paranoica.» (Anyó, 2013: 44). Pero, en realidad, la narración no es adjudicable al personaje sino al narrador (extradiegético, impersonal), como el propio Anyó especifica más adelante. 
evidencia de la imagen que, si bien puede tener también algún grado de imprecisión, ya tiene un nivel de consistencia grande, siempre mayor que la palabra.

El narrador visual de las imágenes de Poema a fumetti propone al lector-espectador unas «realidades» fantásticas traídas de la tradición y otras más novedosas, más personales: las sombras negras y alargadas, las casas espectrales deformadas, las bocas desmesuradas en las que se ven cuatro hileras de dientes enormes, afilados o romos (superior, inferior y laterales), seres imposibles teriomorfos, brujas desnudas volando por los aires, la Tierra que se licúa sobre la pierna de Dios, las caras con cuatro ojos, el cuerpo de Eura que atraviesa la puerta del Más allá, la plasmación de la enfermedad misteriosa que acaba con la muchacha, representada como una especie de rata deforme, la ciudad y el Palacio de los Maníacos como un bosque de edificios inclinados (al modo de Piranesi), la escalera de descenso a los Infiernos como un acordeón desplegado, la muerte como una especie de gran plantígrado oscuro y erguido, la violencia mortal que se insinúa como una sombra y ataca de improviso a una muchacha desnuda, como un rayo negro que cambia a una especie de araña mecánica articulada que atenaza a su víctima, la desangra y convierte en otra extraña araña (Figuras, 8, 9 y 10), el diablo custodio como una chaqueta vacía, las cabezas transparentes de los muertos y las de las almas en pena (con sus manos crispadas como garras) llevadas por la tormenta en las crestas de la Gran Fermeda, las caras monstruosas, cuerpos humanoi-

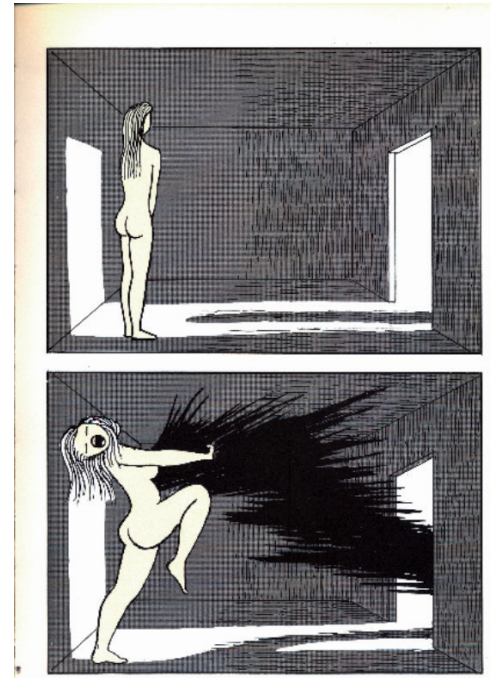

Figura 8

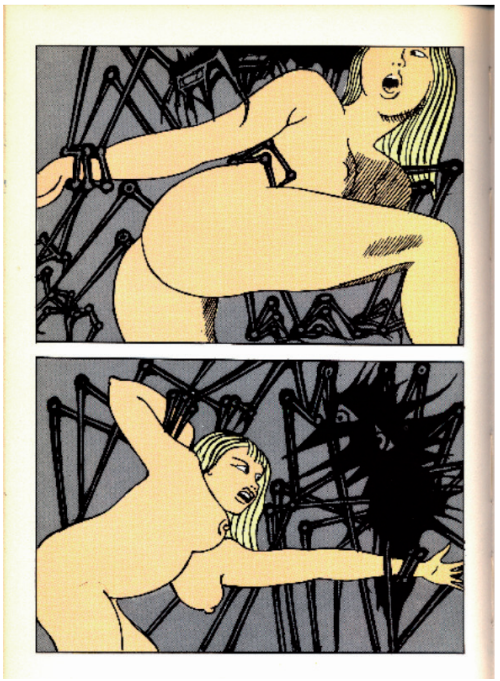

Figura 9 
des erizados de púas, una especie de cerdo flotante, grandes moles mixtas de roca y momia que empuñan un bisturí, una calavera que asoma en la ventanilla de un simón (Figuras 11, 12 y 13), una inquietante cara de niña que se desvanece para materializar las causas del miedo, los esqueletos de los soldados que vagan uniformados por la ciénaga, las melusinas como larvas humanizadas, el cuerpo ondulante de la mujer como aplastada o emergiendo de la

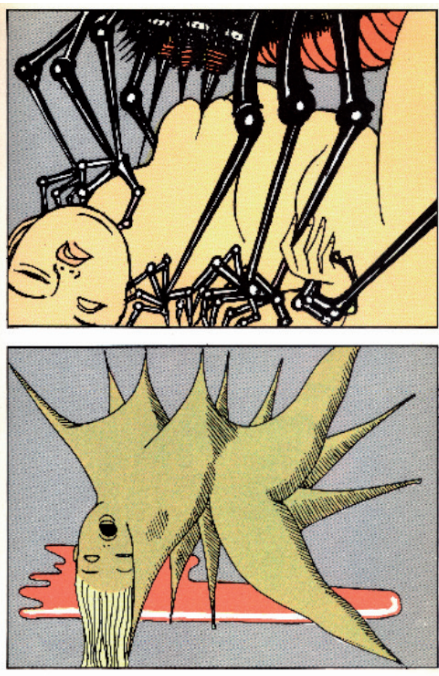

Figura 10

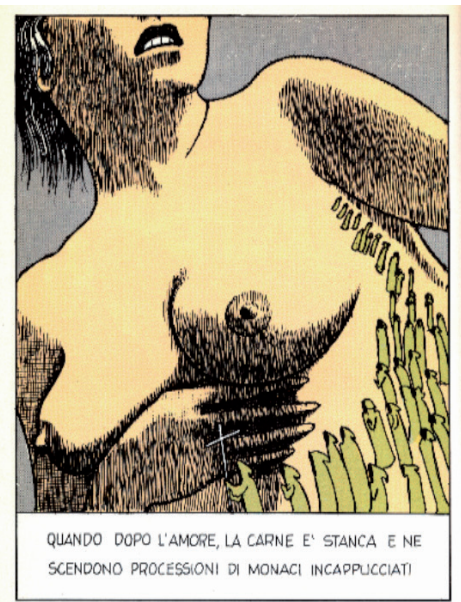

Figura 12

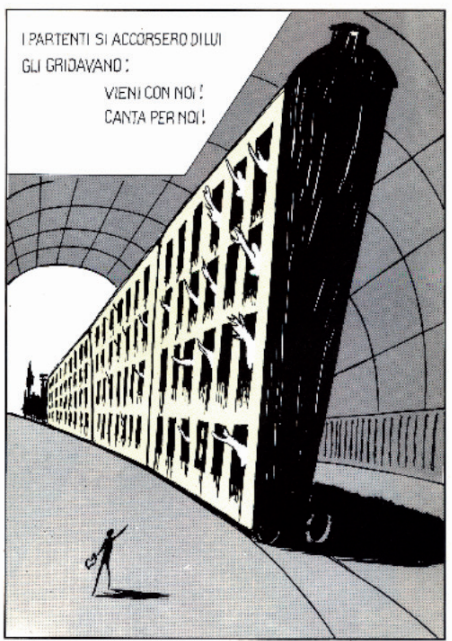

Figura 11

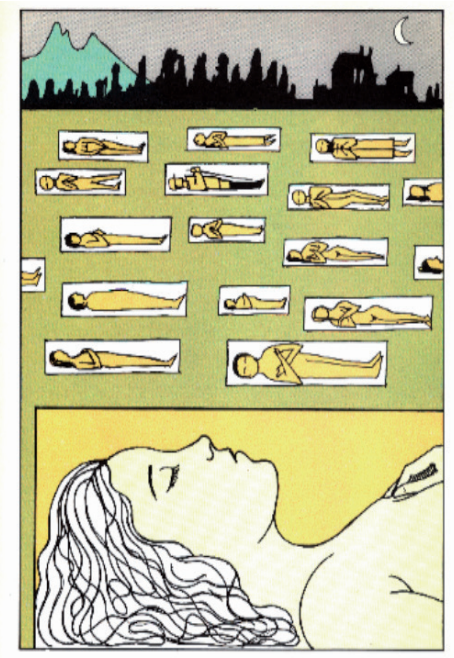

Figura 13 
ciénaga (metáfora del final del coito), el perro espectral que aúlla en la noche y araña la puerta de los amantes, la anciana y tétrica señora que mira al pasar al amante que espera, la procesión de monjes encapuchados que desciende por el vientre de la mujer cansada tras el amor, los muertos incontables que dibujan con sus cuerpos el perfil del pórtico de la catedral de Milán, el tren de los muertos, cuyos vagones son como edificios estrechos de cuatro pisos o la sección del terreno donde pueden verse las sepulturas donde reposan los cuerpos de los muertos. Un buen número de imágenes fantasiosas e imaginativas para dar consistencia y sugerencia visual a esta curiosa reescritura del mito de Orfeo y Eurídice hecha por Dino Buzzati, maestro del género.

\section{BIBLIOGRAFÍA}

AlArcón, Víctor (2013): «De la risa a la inquietud: El humor en la literatura fantástica», en David Roas y Patricia García (eds.), Visiones de lo fantástico (aproximaciones teóricas), e.d.a., Málaga, pp. 73-87.

Alvar, Carlos (1989): «El viaje al Más Allá y la literatura artúrica», en Literatura y fantasía en la Edad Media, Universidad de Granada, Granada, pp. 15-26.

ANYó, Lluís (2013): «El jugador implicado entre dos mundos. Mecanismos de lo fantástico en los videojuegos», en David Roas y Patricia García (eds.), Visiones de lo fantástico (aproximaciones teóricas), e.d.a., Málaga, pp. 39-54.

Bellemin-Nö̈l, Jean (2001): «Notas sobre lo fantástico (Textos de Théophile Gautier)», en David Roas (ed.), Teorías de lo fantástico, Arco/Libros, Madrid, pp. 107-140.

Buzzati, Dino (1996): Los siete mensajeros y otros relatos, traducción de Javier Setó, Alianza Editorial, Madrid. (2004a): El secreto del Bosque Viejo, traducción de Mercedes Corral, Gadir, Madrid. (2004b): La famosa invasión de Sicilia por los osos, dibujos del autor, traducción de María Estébanez, Gadir, Madrid.

(2006a): El desierto de los Tártaros, prólogo de Jorge Luis Borges, traducción de Carlos Manzano, Gadir, Madrid.

(2006b): Poema a fumetti, Arnoldo Mondadori Editore, Milano, 1969.

(2006b): Poema en viñetas. Novela gráfica, dibujos del autor, traducción de Carlos Manzano, Gadir, Madrid.

(2006c): Sesenta relatos, traducción de Mercedes Corral, Acantilado, Barcelona. (2007): Bárnabo de las Montañas, traducción de Carlos Manzano, Gadir, Madrid.

(2008): El Colombre, traducción de Mercedes Corral, Acantilado, Barcelona. (2010): Las noches difíciles, traducción de Atalaire, Acantilado, Barcelona.

CAMpra, Rosalba (2001): «Lo fantástico: una isotopía de la transgresión», en David Roas (ed.), Teorías de lo fantástico, Arco/Libros, Madrid, pp. 153-191. 
Castany Prado, Bernat (2013): «Monstruosidad e infinito en la literatura fantástica española contemporánea», en David Roas y Patricia García (eds.), Visiones de lo fantástico (aproximaciones teóricas), e.d.a., Málaga, pp. 123-145.

García, Patricia (2013): «La "frase umbral", desliz al espacio fantástico», en David Roas y Patricia García (eds.), Visiones de lo fantástico (aproximaciones teóricas), e.d.a., Málaga, pp. 27-38.

Eliade, Mircea (1998): Lo sagrado y lo profano, Paidós, Barcelona /Buenos Aires.

FERnÁndeZ, Teodosio (2001): «Lo real maravilloso de América y la literatura fantástica», en David Roas (ed.), Teorías de lo fantástico, Arco/Libros, Madrid, pp. 283297.

Freud, Sigmund (1998): «Lo siniestro», Revista de Occidente, núm. 201, pp. 101-109.

García Alonso, Almudena, y Juan José Prat Ferrer (2007): «El arquetipo de Orfeo y sus interpretaciones desde el orfismo hasta nuestros días», Clínica y análisis grupal, vol. 99, núm. 29, 2, pp. 71-98.

García GuAL, Carlos (2008): «Relecturas modernas y versiones subversivas de los mitos antiguos», en Juan Herrero Cecilia y Montserrat Morales Peco (coords.), Reescrituras de los mitos en la literatura, Ediciones de la Universidad de Castilla La Mancha, Cuenca, pp. 31-44.

Gonzalo Delgado, Ramiro (2010): «Orfeo y Euridice en el comic», Cuadernos de Filología Clásica Estudios Latinos, 30, 1, pp. 193-216.

Palmieri, Cristina (2016): «Dino Buzzati. Storie scritte e disegnate», en http://mila noartexpo.com/2011/10/18/dino-buzzati-1967-galleria-il-portichetto-di guidopalmieri-a-rho-inaugura-la-personale-di-buzzati/ (última consulta 28/05/2016)

PetrushévsKaia, Liudmila (2011): Érase una vez una mujer que quería matar al bebé de su vecina, Atalanta, Gerona.

Pozo SÁnchez, Begoña (2009): «Dino Buzzati y los margenes de la escritura», Extravío. Revista electrónica de literatura comparada, núm. 4, pp. 62-72 [en línea <http:/ / www.uv.es/extravio>; (última consulta 28/05/2016)].

ReIsz, Susana (2001): «Las ficciones fantásticas y sus relaciones con otros tipos ficcionales», en David Roas (ed.), Teorías de lo fantástico, Arco/Libros, Madrid, pp. 193-221. (2002): «En compañía de dinosaurios», Quimera. Revista de Literatura, núm. 218219, pp. 46-50.

RoAs, David (ed.) (2001): Teorías de lo fantástico, Introducción, compilación de textos y bibliografía de David Roas, Arco Libros, Madrid.

(2011): Tras los límites de lo real. Una definición de lo fantástico, Páginas de Espuma, Madrid.

(2013): «Mutaciones postmodernas: del vampiro depredador a la naturalización del monstruo», en David Roas y Patricia García (eds.), Visiones de lo fantástico (aproximaciones teóricas), e.d.a., Málaga, pp. 91-111.

RoAs, David, y Patricia García (eds.) (2013): Visiones de lo fantástico (aproximaciones teóricas), e.d.a., Málaga.

SALDÍAs R., Gabriel (2013): «Cercanías y fronteras entre lo fantástico y lo distópico», en David Roas y Patricia García (eds.), Visiones de lo fantástico (aproximaciones teóricas), e.d.a., Málaga, pp. 173-188. 
Todorov, Tzvetan (1982): Introducción a la literatura fantástica, Ediciones Buenos Aires, Barcelona.

Trabado Cabado, José Manuel (comp.) (2013): La novela gráfica. Poéticas y modelos narrativos, Arco/Libros, Madrid.

VicianA, Sergi (2013): «El zombi como cuestionamiento de los límites de lo fantástico», en David Roas y Patricia García (eds.), Visiones de lo fantástico (aproximaciones teóricas), e.d.a., Málaga, pp. 113-121. 
